\title{
Buspirone Attenuates Synaptic Activation of Hippocampal Pyramidal Cells
}

\author{
Michael D. Mauk, ${ }^{a}$ Stephen J. Peroutka, and Jeffery D. Kocsis ${ }^{a}$ \\ Department of Neurology, Stanford University School of Medicine, Stanford, California 94305, and Palo Alto Veterans \\ Administration Medical Center, Palo Alto, California 94304
}

The actions of 5-hydroxytryptamine (5-HT) and buspirone, an anxiolytic agent that displays high and selective affinity for 5-HT , $_{\text {A }}$ receptor sites, on synaptic activation of hippocampal CA1 pyramidal cells were studied in vitro. Whereas 5-HT application leads to a rapid hyperpolarization and decreased input resistance in pyramidal cells, buspirone has no measurable effects on membrane potential and input resistance. However, unlike 5-HT, buspirone application leads to a gradual and reversible reduction in excitatory postsynaptic potentials (EPSPs) elicited by stimulation of afferents in the stratum radiatum. Concurrent with this attenuation of the EPSP, buspirone decreases the excitability of afferent fibers in the stratum radiatum as evidenced by conduction slowing, increased refractory period, and decreased ability to generate repetitive impulses. 5-HT has no measurable effect on the afferent fibers. The attenuation of the EPSPS and the decrease in afferent fiber excitability appear to be independent of 5-HT receptors as 5-HT neither shares nor antagonizes the effects of buspirone. Thus, both 5-HT and buspirone can contribute to reduced spike activity in pyramidal cells, but they do so via different mechanisms: 5-HT hyperpolarizes pyramidal cells whereas buspirone attenuates their synaptic activation, possibly via action on the presynaptic fibers in the stratum radiatum.

Buspirone is a recently developed compound that displays potent anxiolytic action in animal models (Riblet et al., 1984; Davis et al., 1985) and in humans (Goldberg and Finnerty, 1979; Schuckit, 1984). It lacks the sedative, addictive, and memoryimpairing side effects of the benzodiazepines (Moskowitz and Smiley, 1982) and has recently been approved for clinical use in the United States. Unlike the benzodiazepine anxiolytics, buspirone does not bind to the benzodiazepine-chloride ionophore complex (Peroutka, 1985). However, radioligand binding studies indicate that buspirone displays high and selective affinity for the 5-hydroxytryptamine $1 \mathrm{~A}\left(5-\mathrm{HT}_{1 \mathrm{~A}}\right)$ receptor site (Glaser and Traber, 1983; Riblet et al., 1984; Peroutka, 1985, 1986).

The potential clinical value of buspirone has promoted much interest in its electrophysiological actions (VanderMaelen and

Received Sept. 22, 1986; revised June 15, 1987; accepted June 17, 1987.

This work was supported by the McKnight Foundation, the NIH (NS 1215111, NS 23560-01), and the Medical Research Service of the Veterans Administration.

Correspondence should be addressed to Jeffery D. Kocsis, Ph.D., Neurology (127), VA Medical Center, 3801 Miranda Avenue, Palo Alto, CA 94304.

a Present address: Department of Neurology, Yale University School of Medicine, New Haven, C1 06510.

Copyright C 1988 Society for Neuroscience $0270-6474 / 88 / 010001-11 \$ 02.00 / 0$
Wilderbrand, 1984; Andrade and Nicoll, 1985, 1987; Trulson and Arasteh, 1986; Peroutka et al., 1987; Rowan and Anwyl, 1987). The electrophysiological actions of buspirone are also of interest in light of the similar anti-anxiety effects of buspirone and benzodiazepines despite the dissimilarity of the brain receptors to which these agents bind. Several authors have suggested that the anxiolytic properties of buspirone are mediated by its interaction with 5-HT receptors (Andrade and Nicoll, 1985, 1987; Peroutka, 1985; VanderMaelen et al., 1986). The purpose of the present studies is to compare the electrophysiological actions of buspirone and 5-HT. The hippocampus appears to be an ideal region in which to make this comparison: the $5-\mathrm{HT}_{\mathrm{IA}}$ receptor subtype is abundant in the hippocampus (Pazos and Palacios, 1985) and the effects of 5-HT on hippocampal pyramidal cells are well characterized (Jahnsen, 1980; Segal, 1980; VanderMaelen, 1985).

In the present study we compare the effects of 5-HT and buspirone on membrane properties of hippocampal pyramidal cells and on the synaptic activation of these cells elicited by stimulation of afferents in the stratum radiatum. The results indicate that buspirone and 5-HT both contribute to reduced activity in pyramidal cells, but that they do so through different mechanisms; 5-HT has clear postsynaptic actions, while buspirone attenuates synaptic activation of pyramidal cells and concurrently alters the excitability of the presynaptic fiber.

\section{Materials and Methods}

Hippocampal slices were prepared and maintained in vitro using standard procedures. Female Wistar rats were deeply anesthetized with sodium pentobarbital $(70 \mathrm{mg} / \mathrm{kg}$, i.p.) and rapidly exsanguinated by carotid section. The dorsal surface of the brain was exposed, and a 5 $\mathrm{mm}$ block of one hemisphere removed by making cuts at midline and at an angle $35^{\circ}$ rostral to the coronal plane. The tissue block was quickly placed in cold $\left(4^{\circ} \mathrm{C}\right)$, modified Kreb's solution, glued to the stage of a vibratome with cyanoacrylate, and $400 \mu \mathrm{m}$ slices were cut from the entire block. The hippocampi were dissected free and placed in a submersion-type brain slice chamber. The chamber was continuously perfused with the modified Kreb's solution $(5 \mathrm{ml} / \mathrm{min})$ and maintained at $34-37^{\circ} \mathrm{C}$. Sections were allowed to stabilize at least $1 \mathrm{hr}$ prior to all experiments. The modified Kreb's solution consisted of the following (in mM): $\mathrm{NaCl}, 124 ; \mathrm{KCl}, 3.0 ; \mathrm{MgCl}_{2}, 2.0 ; \mathrm{CaCl}_{2}, 2.0 ; \mathrm{NaHCO}_{3}, 26.0$; $\mathrm{NaH}_{2} \mathrm{PO}_{4}, 1.3$; and dextrose, 10.0. The solution was saturated with $95 \%$ $\mathrm{O}_{2}$ and $5 \% \mathrm{CO}_{2}$. All drugs were administered via bath application dissolved in the Kreb's solution. In experiments utilizing low calcium and high magnesium, $\mathrm{CaCl}_{2}$ was reduced to $0.3 \mathrm{mM}$ and $\mathrm{MgCl}_{2}$ increased to $6.0 \mathrm{~mm}$.

Pyramidal cells in the CAl region were orthodromically activated by constant current cathodal pulses ( $40 \mu \mathrm{sec}$ duration) delivered through tungsten microelectrodes positioned in the stratum radiatum (Fig. $1 A$ ). Field potentials elicited by this stimulation were recorded in the pyramidal cell layer (stratum pyramidale) and the dendritic layer (stratum radiatum) with glass microelectrodes filled with $3 \mathrm{M} \mathrm{NaCl}$ (DC resistance 

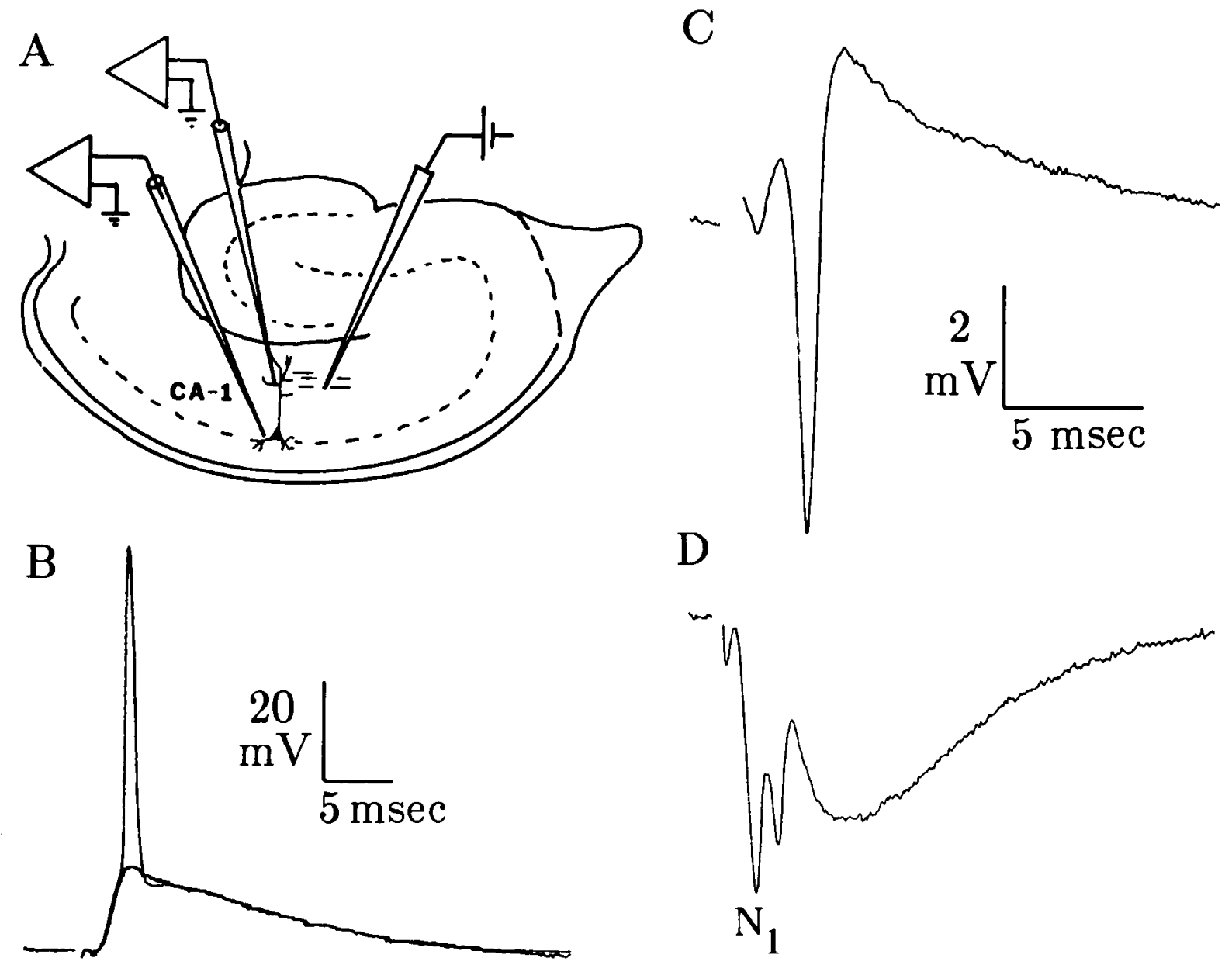

Figure 1. A, Schematic representation of the in vitro slice preparation and the arrangement of the stimulating and recording electrodes. Afferent fibers were activated by constant-current pulses delivered through a tungsten microelectrode positioned in the stratum radiatum. Field potentials elicited by this stimulation were recorded in adjacent regions of the stratum pyramidale $(C)$ and stratum radiatum $(D)$. Intracellular recordings were also obtained from pyramidal cell somata. In the example shown in $(B)$, stimulation intensity was adjusted to threshold for spike initiation ( 2 traces are superimposed). Positive potential changes are upward for all traces of this and subsequent figures. The calibration for $C$ and $D$ is the same.

5-20 M $\Omega$ ). In the stratum radiatum the field potentials elicited by the stimulation consist of a short latency negative potential (the $N_{1}$ potential) corresponding to action potential currents of the afferent fibers (Fig. $1 D$ ). This is followed by another negative potential corresponding to sink currents of the excitatory postsynaptic potentials (EPSPs). In some responses there is a small positive potential superimposed on the second negativity, corresponding to source currents of distal action potentials in the postsynaptic pyramidal cells.

These events are also apparent in the field potentials recorded from stratum pyramidale (Fig. 1C). An initial low-amplitude negative potential corresponds to presynaptic action potential activity. This is followed by a positive potential reflecting source currents of distal EPSPs. A large negative potential arises from the EPSP and corresponds to local sink currents associated with synchronous action potential activity (population spike) in the pyramidal cells. These signals were amplified, lowpass-filtered $(10 \mathrm{kHz})$, digitized with a Nicolet 1170 signal averager, and stored on magnetic tape.

Intracellular recordings were obtained from pyramidal neuron somata using glass microelectrodes filled with $4 \mathrm{~m}$ potassium acetate and beveled to $\mathrm{DC}$ resistances of $130-180 \mathrm{M} \Omega$. Impaled neurons were studied only if the recorded resting potential was $>-65 \mathrm{mV}$ and stable, the EPSP was large, and spike amplitude was at least $60 \mathrm{mV}$. Data from the intracellular recordings were digitized and stored on video cassettes using a Neuro Data 434 digitizer (DC-20 kHz). An example recording is shown in Figure $1 B$. In most experiments, buspirone was applied in the bath at a concentration of $50 \mu \mathrm{M}$. In previous experiments this concentration was determined to be the $\mathrm{EC}_{50}$ for reduction of the population spike (Peroutka et al., 1987). In some intracellular experiments a concentration of $100 \mu \mathrm{M}$ was applied in order to decrease the time required to produce effects and increase the likelihood of reversing the effects during the time a stable impalement could be maintained.

\section{Results}

Synaptic activation of pyramidal cells

The effects of buspirone on synaptic activation of hippocampal pyramidal cells are revealed by changes in the field potentials recorded from stratum pyramidale and stratum radiatum, as well as by changes in intracellular responses recorded from pyramidal cell somata. In each case, the results indicate that buspirone produces a progressive attenuation of monosynaptic activation of pyramidal cells. Buspirone application leads to a gradual decrease in amplitude of the population spike and population EPSP. Superimposed traces of field potential recordings from stratum pyramidale 2 and 30 minutes following buspirone application demonstrate the gradual reduction in both the population EPSP and spike (Fig. 2, $A, B$ ). Simultaneous field potential recordings in stratum radiatum also reveal a reduction in EPSP amplitude produced by buspirone (Fig. 2, D, E). Previous studies have shown that this attenuation of the population spike is dose dependent and reversible (Peroutka et al., 1987). Intracellular recordings also demonstrate that buspirone 

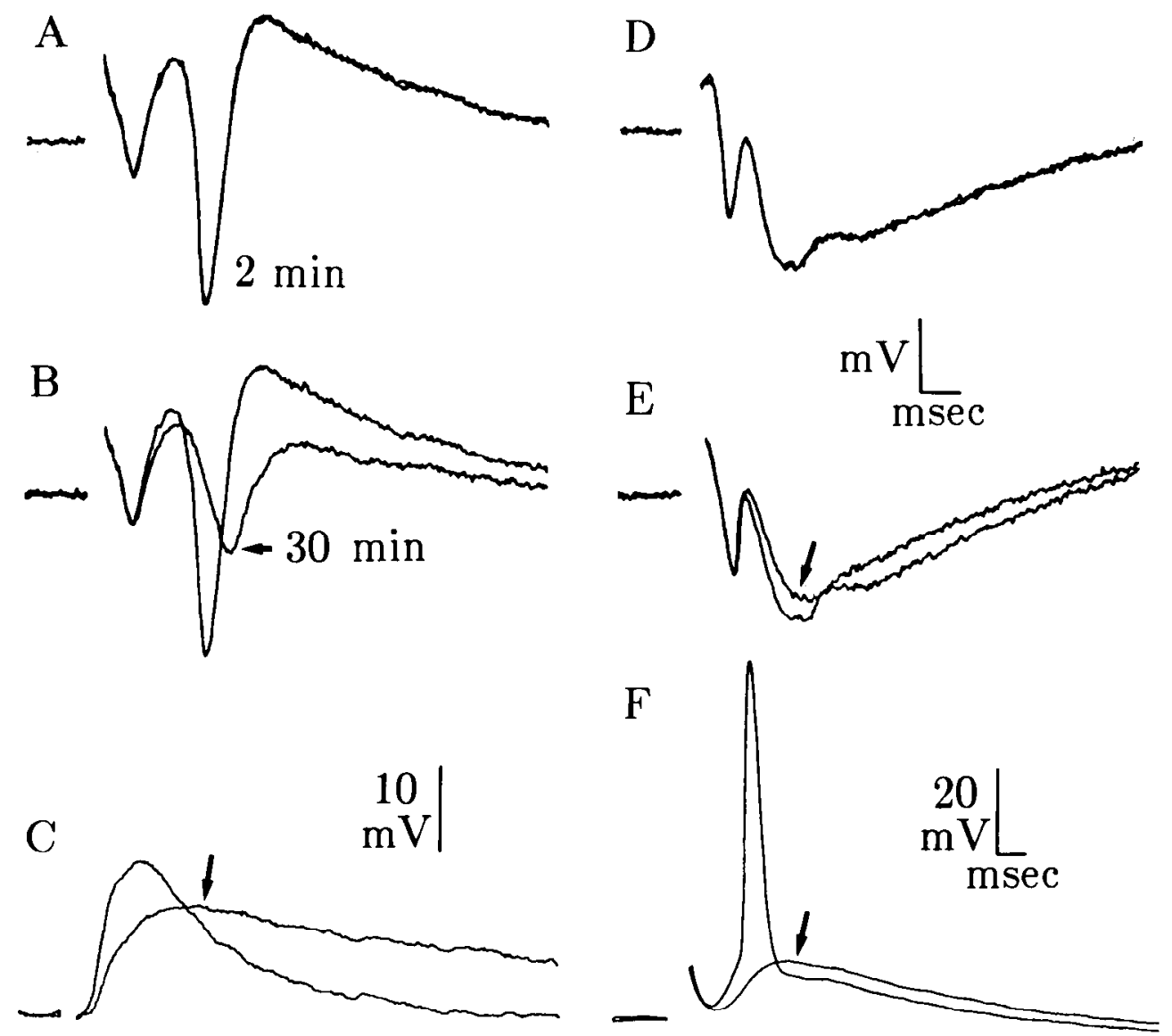

Figure 2. Effects of buspirone on synaptic activation of pyramidal cells. $A$, Superimposed population spikes recorded prior to, and $2 \mathrm{~min}$ following the application of buspirone $(50 \mu \mathrm{M}) . B$, The same control response as in $A$ and a response recorded $30 \mathrm{~min}$ following buspirone application (arrow). D, Superimposed population EPSP recordings from the stratum radiatum recorded prior to and 2 minutes following buspironc application. $E$, Samc control response as in $D$ and a response recorded 30 min following buspirone application (arrow). There is also an increase in the latency of the $N_{1}$ component of the stratum radiatum field potential that is not readily apparent at this slow sweep speed (see Fig. 7). The responses in $D$ and $E$ were recorded simultaneously to those in $A$ and $B$ using a second recording electrode. $C$ and $F$, Intracellular recording from a pyramidal cell soma with superimposed sweeps taken prior to and $20 \mathrm{~min}$ following buspironc application (arrows). $C$, Superimposed EPSPs showing the attenuation produced by buspirone ( $a r$ row). $F$, Two traces at lower gain and higher stimulation intensity showing decrease in EPSP and concomitant spike failure produced by buspirone. Time calibration is the same for $C$ and $F$. Calibration for $A, B, D$, and $E$ is the same. decreases EPSP amplitude and increases the intensity of afferent stimulation required to elicit an action potential (Fig. 2, $C, F$ ).

These effects of buspirone are in contrast to those of 5-HT in the hippocampus. Intracellular recordings from pyramidal neurons reveal that application of 5-HT leads to a rapid hyperpolarization of pyramidal cells and in most cells a concomitant increase in EPSP or spike amplitude, as would be expected to occur with the increased driving force provided by hyperpolarization (Peroutka et al., 1987) (Fig. 3, C, F). Under stimulation and recording conditions optimizing activation of pyramidal cells (optimal stimulation electrode shape and short conduction distance), this hyperpolarization results in a rapid (peak in 1-2 min) increase in amplitude of the population spike and a slight increase in the population EPSP (Fig. 3, $A, D$ ). These effects diminish over the course of 5-30 min, but generally the amplitude of the population spike remains greater than baseline (Fig. 3, $B, E$ ).

Combined application of buspirone and 5-HT (50 $\mu \mathrm{M}$ each) was used to assess whether each compound antagonizes or enhances the effects of the other. As can be seen in Figure 4, buspirone attenuates the increase in population spike produced by 5 -HT. This supports the notion that the hyperpolarization produced by $5-\mathrm{HT}$ is mediated by activation of $5-\mathrm{HT}_{1 \mathrm{~A}}$ receptors and suggests that buspirone may act as an antagonist at $5-\mathrm{HT}_{1 \mathrm{~A}}$ sites. Figure 4 also clearly reveals that 5-HT neither antagonizes nor enhances the gradual attenuation of the population spike produced by buspirone. These data provide support that this attenuation of synaptic activation of pyramidal cells by buspirone is independent of 5-HT receptors.

\section{Pyramidal cell membrane properties}

The differential action of buspirone and 5-HT is also supported by intracellular recordings from pyramidal neurons. The demonstration in previous experiments that application of 5-HT increases potassium conductance in hippocampal pyramidal neurons (Segal, 1980) is supported by the present data. Application of 5-HT results in a rapid hyperpolarization and decrease in input resistance (Fig. $5, A, B, D$ ). In most cells ( 8 of 11) the hyperpolarization is accompanied by an increase in EPSP amplitude (Figs. $3 C$ and $5 A$ ) or an increase in the amplitude of the action potential (Fig. $3 F$ ). In the remaining 3 cells hyperpolarization and decreased input resistance were accompanied by an initial increase followed by a rapid reduction in EPSP amplitude (Fig. 5A).

The effect of buspirone application as revealed by intracellular recordings is an attenuation of synaptic activation of pyramidal cells that appears not to involve changes in pyramidal cell membrane properties. In contrast to $5-\mathrm{HT}$, buspirone has no clear effect on resting potential or input resistance (Fig. $5, B, C, E$ ). Indeed, buspirone produces only a slight decrease in EPSP amplitude over the time in which 5 -HT has pronounced effects $(0$ 5 min; Fig. $5 C$ ). Despite no noticeable change in membrane potential or input resistance, there occurs over 10-20 min a gradual reduction in EPSP amplitude (Fig. 6, $A-C$ ). This reduction is accompanied by an increase in the stimulation intensity required to produce a spike (Fig. $6 \mathrm{C}$ ). These effects are reversible: Following a 10-15 min wash with drug-free solution, the EPSP amplitude and action potential threshold return to 
Figure 3. Effects of 5-HT on synaptic activation of pyramidal cells. $A$, Superimposed population spikes recorded prior to and 2 min following the application of 5-HT (arrow) demonstrating the large increase in the population spike. $B$, Same control response as in $A$ and a response recorded $30 \mathrm{~min}$ following 5-HT application (arrow). D, Superimposed population EPSP recordings from the stratum radiatium recorded prior to and $2 \mathrm{~min}$ following 5-HT application (arrow). E, Same control response as in $D$ and a response recorded $30 \mathrm{~min}$ following the application of 5-HT. The responses in $D$ and $E$ were recorded simultaneously to those in $A$ and $B$ using a second recording electrode. $C$ and $F$, Intracellular recording from the soma of a pyramidal cell with superimposed sweeps taken prior to and 2 min following 5-HT application (arrows). $C$, Traces showing the hyperpolarization and increase in EPSP amplitude produced by 5-HT. $F$, Traces at lower gain and at a stimulation intensity sufficient to elicit a spike. The baselines have been superimposed to show the increase in spike amplitude and EPSP produced by 5-HT (arrows). The degree of hyperpolarization produced in this cell is shown in the inset. Time calibration is the same for $C$ and $F$; calibration for $A, B, D$, and $E$ is the same.
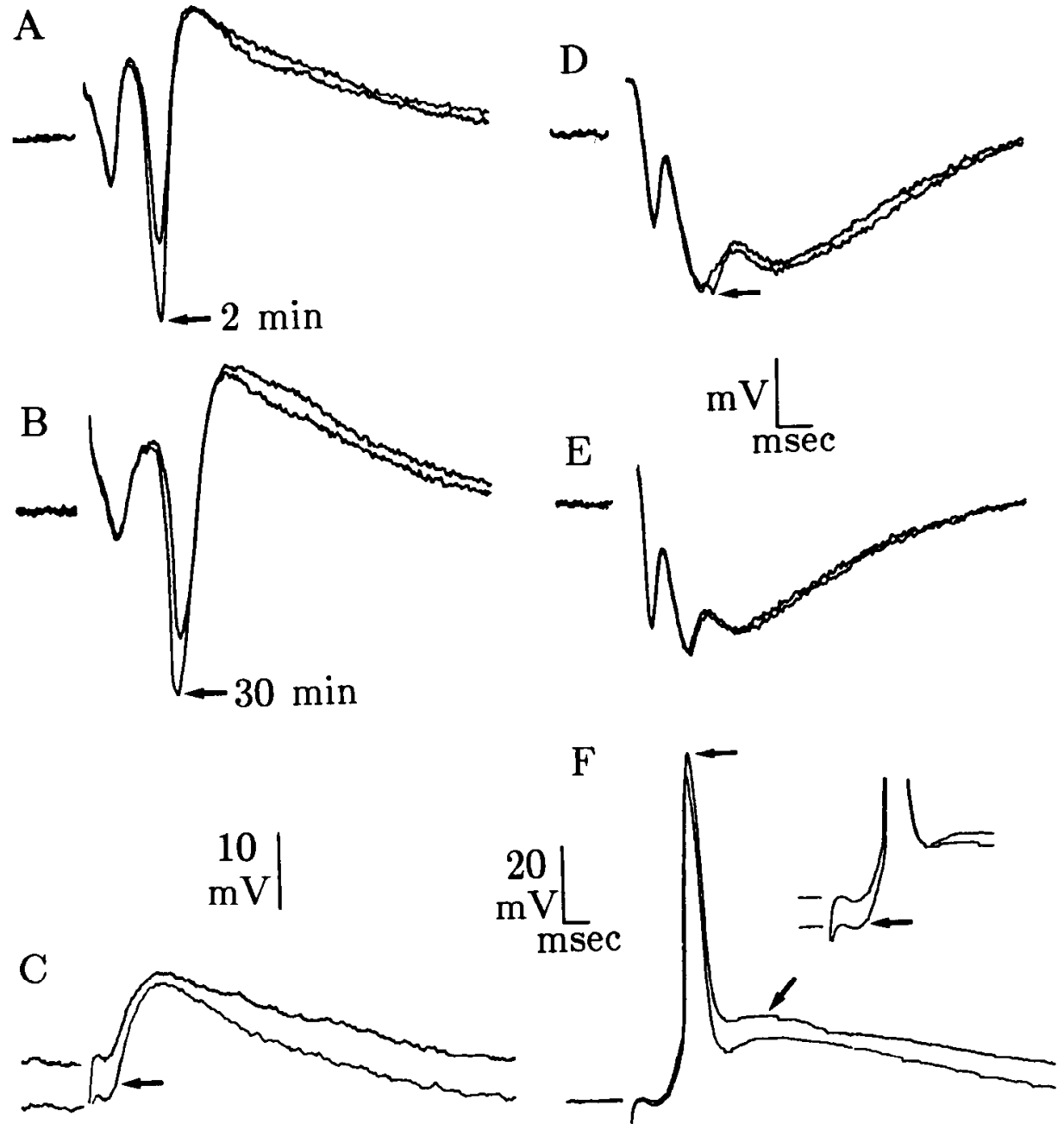

near baseline (Fig. $6 \mathrm{C}$ ). The gradual decrease in EPSP amplitude and increase in threshold stimulation intensity could clearly account for the changes in population spike and population EPSP produced by buspirone. In support, the time course of

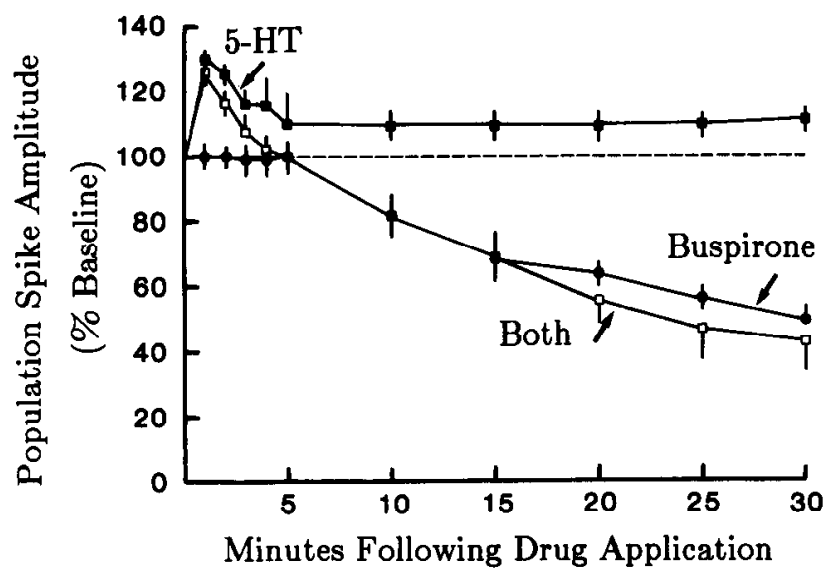

Figure 4. Time course of the effects of buspirone, 5-HT, and combined application on the population spike amplitude. Bars indicate SEM $(n=$ 8,5 , and 5 for buspirone, 5-HT, and "both," respectively). Combined application of buspirone and 5-HT (50 $\mu \mathrm{M}$ each) leads to effects similar to those of each compound alone with the exception that the initial effect of 5-HT is slightly attenuated in the presence of buspirone. the reduction in EPSP observed with intracellular recordings is consistent with the changes seen with extracellular field potentials.

These data also reinforce the distinctiveness of the actions of 5-HT and buspirone. The effects of 5-HT appear to be mediated by direct action on the pyramidal cells. The changes in population spike and population EPSP may be explained by the 5-HT-induced increase in potassium conductance and the concomitant hyperpolarization. In contrast, buspirone has no noticeable direct effects on the pyramidal cells, yet its application leads to a prominent attenuation of synaptic activation of pyramidal cells. This suggests that buspirone may affect some aspect of the synaptic transmission process or may affect the presynaptic axons or terminals. Analysis of the presynaptic component of the stratum radiatum field potential provides support for action at the presynaptic fibers or terminals.

\section{Afferent fibers in the stratum radiatum}

As mentioned previously, the initial negative potential $\left(\mathrm{N}_{1}\right)$ recorded in the stratum radiatum corresponds to synchronous action potential currents of the afferent axons. The presynaptic fibers make en passant synaptic contacts onto pyramidal cell dendrites. Therefore, the recordings from the presynaptic fibers reflect action potential currents of the afferent fibers as well as currents at the terminal region.

Application of buspirone leads to a progressive increase in 

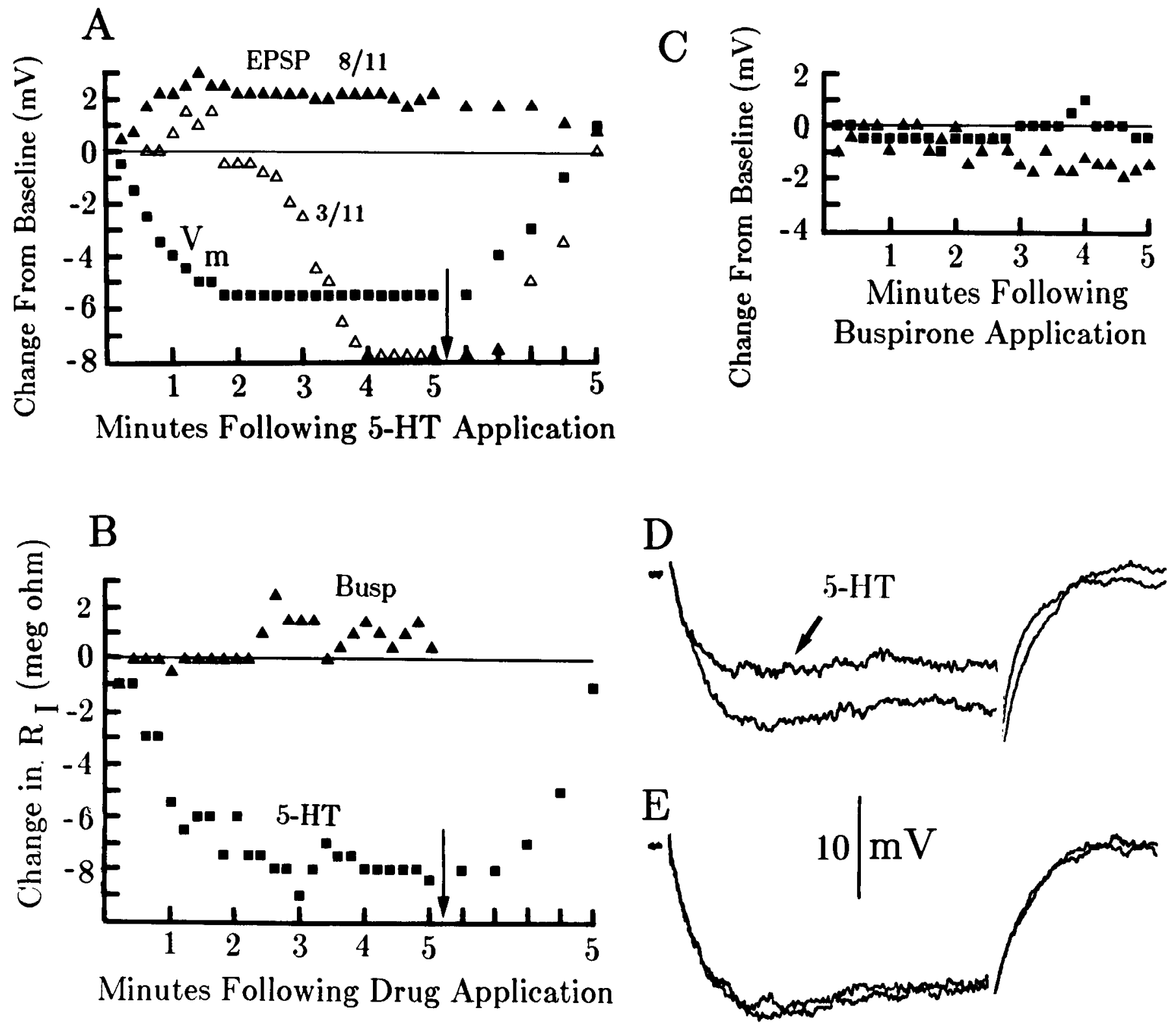

Figure 5. A, Effects of 5-HT application on membrane potential $\left(V_{m}\right.$, squares) and EPSP amplitude (triangles) in 11 pyramidal cells. 5-HT produces a rapid and reversible hyperpolarization (the downward arrow denotes wash with drug-free solution). In 8 of the 11 cells this hyperpolarization was accompanied by an increase in EPSP amplitude (solid triangles), whereas in 3 of the 11 cells there was an initial increase in EPSP followed by a large and reversible decrease (open triangles). B, 5-HT (squares) also produced a decrease in input resistance $(n=4)$, whereas buspirone (triangles) did not $(n=5)$. The change in input resistance was mcasured by the potential change produced by $120 \mathrm{msec}, 0.5 \mathrm{nA}$ hyperpolarizing pulses. $C$, Effects of buspirone application on membrane potential (squares) and EPSP amplitude (triangles) in 6 pyramidal cells over the first 5 min following application. $D$ and $E$, Superimposed traces of the voltage deflection produced by hyperpolarizing pulses delivered through the recording electrodes. The decrease in input resistance produced by 5 -HT application is illustrated in $D$ by the diminished response (arrow). $E$, Buspirone ( 20 min in this example) does not alter input resistance, as revealed by no change in the voltage deflection produced by the hyperpolarizing pulses.

the latency of the $\mathrm{N}_{1}$ potential (Fig. $7, A, B$ ), and produces changes that are functionally equivalent to an increase in the refractory period. These effects are reversible (Fig. $7 B$ ) and their time course parallels the reduction in EPSP and population spike amplitude produced by buspirone. The apparent change in refractory period is revealed by double-stimulation experiments in which a test pulse is preceded at various intervals by a conditioning pulse. A standard recovery curve plotting the latency of the test $N_{1}$ potential versus the interval between the conditioning and test pulses is shown in Figure $7 C$. In the drugfree solution an interstimulus interval of 2 msec yields a large increase in $\mathrm{N}_{1}$ latency. This decrease in conduction velocity indicates that the fibers are propagating in the relative refractory period (Erlanger and Gasser, 1937). However, at interstimulus intervals of 5-150 msec a decrease in $N_{1}$ latency occurs. This period of supernormal axon conduction velocity has been demonstrated in several axon preparations (see Swadlow et al., 1980, for an overview). Application of buspirone ( $50 \mu \mathrm{M}, 25 \mathrm{~min}$ ) extends the refractory period and reduces the degree of supernormal conduction velocity, especially with the shorter intervals (Fig. 7C). For example, in the presence of buspirone, paired stimulus presentation at an interstimulus interval of $5 \mathrm{msec}$ 

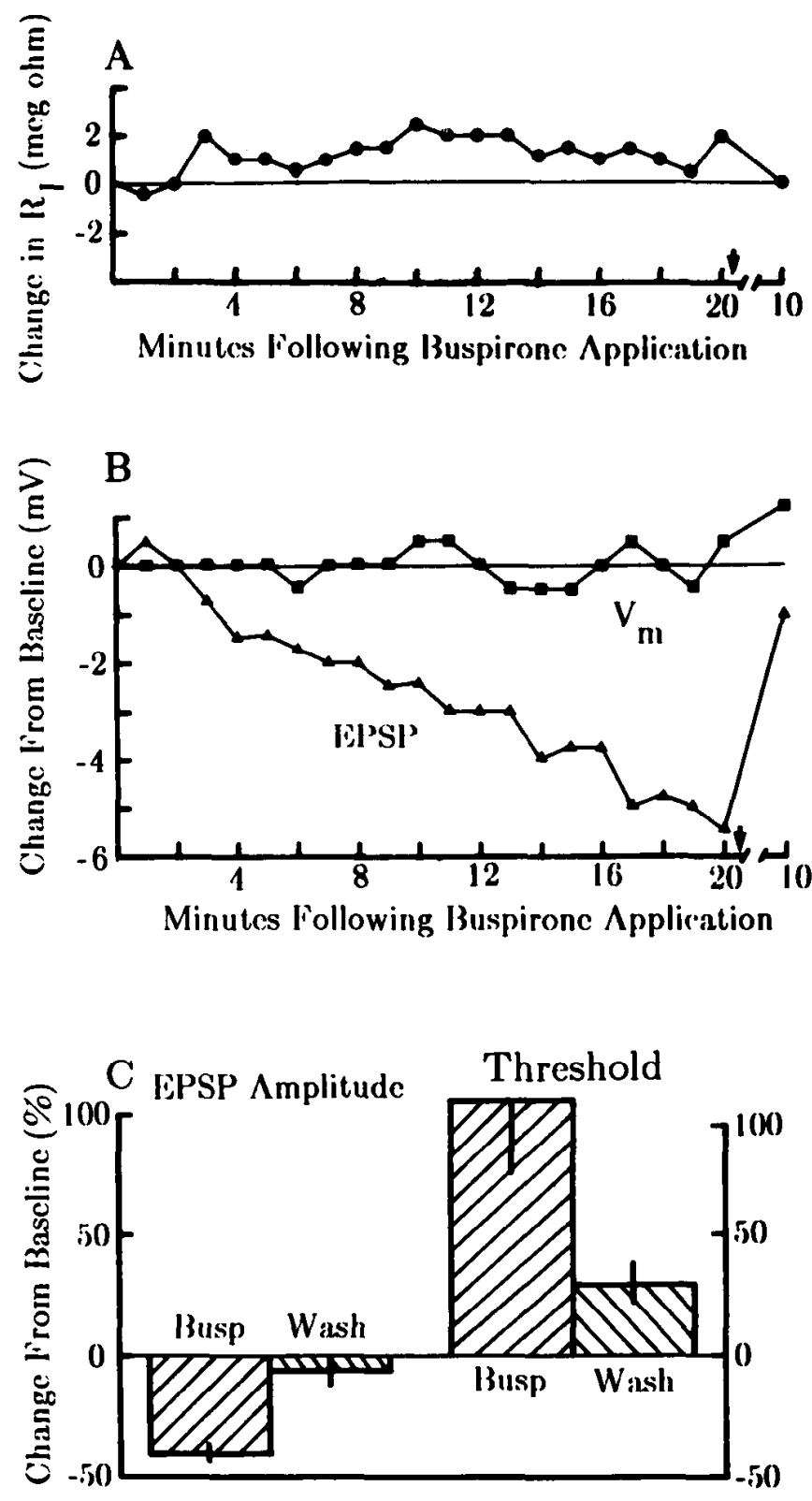

Figure 6. $A$ and $B$, Over the course of $20 \mathrm{~min}$ buspirone decreases the EPSP amplitude yet has no significant effect on input resistance and membrane potential $(n=2)$. This effect is reversible, the arrows in $A$ and $B$ indicate wash with drug free solution. $C$. Buspirone produces a reversible decrease in EPSP amplitude and increase in threshold stimulation intensity (measured $20 \mathrm{~min}$ after buspirone application and 10 min after wash). The data are represented as the percentage of the prebuspirone baseline; the error bars denote SEM $(n=7$ and 5 for EPSP and threshold, respectively).

results in an increase in $N_{1}$ latency and a decrease in amplitude (Fig. 7D2), indicating that the axons are refractory. In the drugfree solution the same interstimulus interval results in supernormal conduction velocity, as indicated by decreased $N_{1}$ latency (Fig. 7Dl).

In contrast to buspirone, application of 5-HT has no measurable effect on the presynaptic fibers (Fig. 8). There is no change in baseline $\mathrm{N}_{1}$ latency (Fig. $8, A, B$ ), nor is there a change in the refractory and supernormal periods (Fig. $8, C, D$ ).

These effects of buspirone on the $N_{1}$ potential are also present when voltage-sensitive calcium channels are blocked by bathing the slice in Kreb's solution containing low $\mathrm{Ca}^{2+}$ and high $\mathrm{Mg}^{2+}$, 0.3 and 6.0, respectively. The low $\mathrm{Ca}^{2+} /$ high $\mathrm{Mg}^{2+}$ solution has slight effects on both the baseline $\mathrm{N}_{1}$ latency (Fig. $9 B$ ) and on the supernormal excitability produced by double stimulation (Fig. 9C). Addition of buspirone to the low $\mathrm{Ca}^{2+} /$ high $\mathrm{Mg}^{2+}$ solution produces the same effects on the $\mathrm{N}_{1}$ potential observed in the normal solution: an increase in baseline $\mathrm{N}_{1}$ latency (Fig. 9, $A, B$ ) and an extended refractory period (Fig. 9, $C, D$ ). These data suggest that the effect of buspirone on the presynaptic fibers does not involve attenuation or block of voltage-sensitive $\mathrm{Ca}^{2+}$ channels and also support a direct action of buspirone on the presynaptic fibers rather than an indirect effect secondary to postsynaptic events.

Application of buspirone also decreases the ability of the afferent fibers to follow high-frequency stimulation. To assess this, stimulation trains of $1 \mathrm{sec}$ duration and frequencies ranging from 2 to $50 \mathrm{~Hz}$ were delivered. Repetitive stimulation increases extracellular potassium concentration, which in turn can alter the excitability of the afferent fibers (Poolos et al., 1985, 1987). A large proportion of this activity-dependent potassium accumulation is derived from activation of postsynaptic elements (Poolos et al., 1985, 1987). Thus, in order to prevent the confounding influcnce of clcvated extracellular potassium, the effects of buspirone on the frequency-following capabilities of the afferent fibers were tested while synaptic transmission was blocked by low $\mathrm{Ca}^{2+} /$ high $\mathrm{Mg}^{2+}$. The effects of repetitive stimulation were assessed by comparing the latency of the response elicited by the first pulse in the train (baseline) with that of the response produced by the last pulse. In these experiments, as before, buspirone produced an increase in baseline latency of the $\mathrm{N}_{1}$ potential. In the presence of buspirone there is also a frequency-dependent increase in the latency of the $N_{1}$ potential that is apparent at frequencies as low as $20 \mathrm{~Hz}$ (Fig. 10).

\section{Discussion}

The major finding of the present study is that synaptic activation of hippocampal pyramidal cells by stimulation of afferents in the stratum radiatum is attenuated by the anxiolytic buspirone, possibly via an action on the presynaptic fibers. Application of buspirone causes a progressive decrease in the population EPSP and spike, a decrease in the amplitude of the intracellularly recorded EPSP, and an increase in the stimulation intensity required to elicit a spike. Concomitant with this decrease in synaptic activation of the pyramidal cells is a reduction in the excitability of the presynaptic fibers, as evidenced by slowed conduction, increased relative refractory period, and a reduction in the ability of the fibers to generate repetitive impulses. Previous experiments have shown that the effects of buspirone on the population spike are dose-dependent and reversible (Peroutka et al., 1987). The present data also demonstrate the reversibility of buspirone's attenuation of synaptic activation of pyramidal cells and of its action on the presynaptic fiber volley.

Although both 5-HT and buspirone lead ultimately to decreased spike activity in pyramidal cells, their actions are mediated by different cellular mechanisms. 5-HT hyperpolarizes pyramidal cells and thereby increases the amount of afferent input required to elicit a spike. In contrast, buspirone appears to have no direct action on the membrane properties of pyramidal neurons; it produces no detectable change in membrane potential or input resistance. Indeed, the only effect observed in the pyramidal cells is a decrease in the amplitude of stimulation-evoked EPSP and a concomitant increase in stimulation 
A

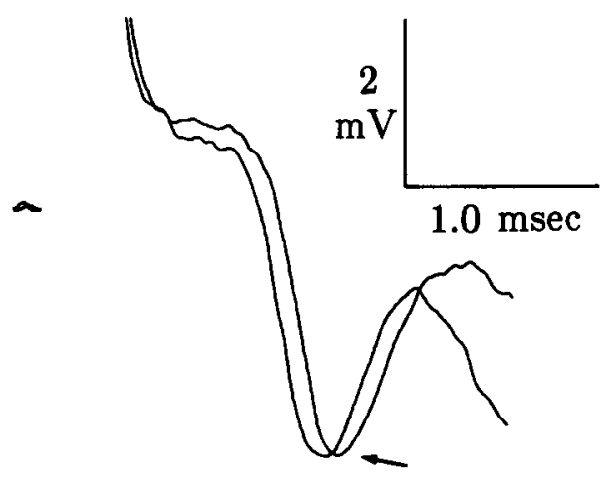

B

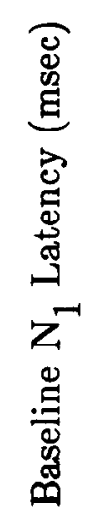

$\mathrm{C}$

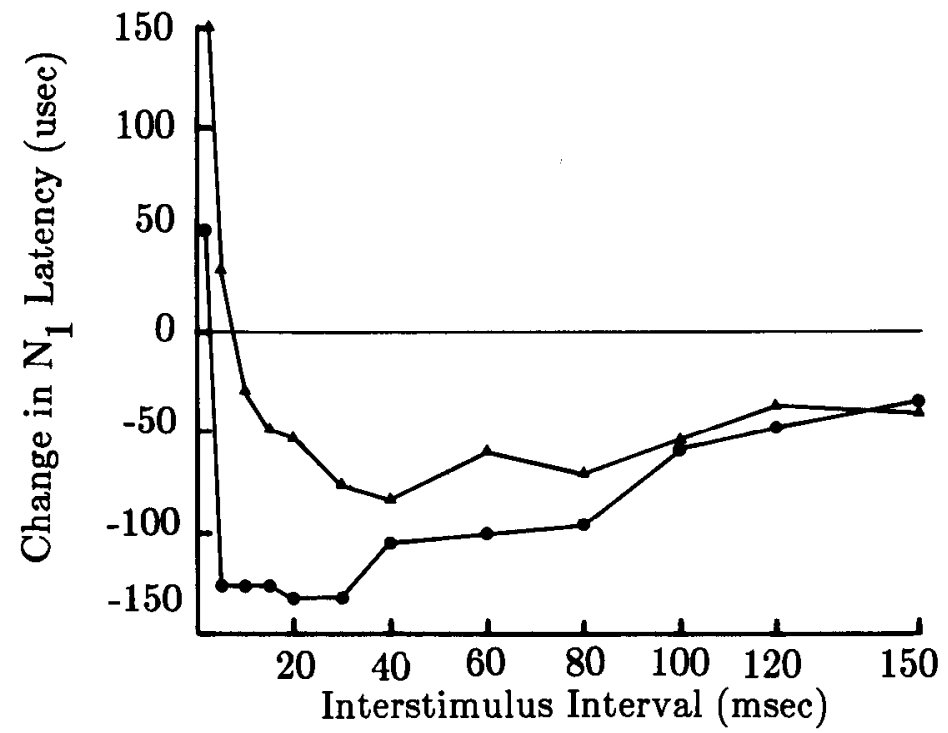

D

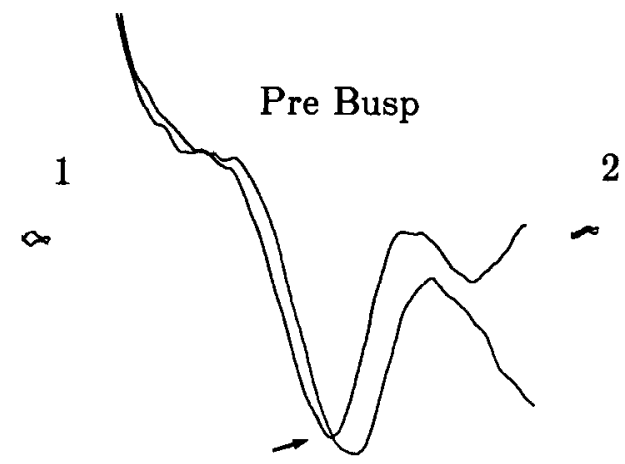

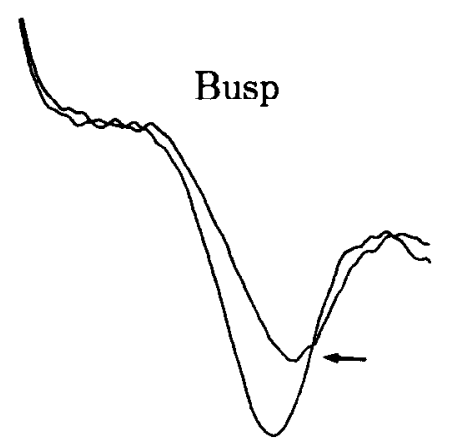

Figure 7. Effects of buspirone $(50 \mu \mathrm{M})$ on conduction properties of the afferent fibers in the stratum radiatum. $A$, Superimposed $\mathrm{N}_{1}$ responses before and after (arrow) buspirone ( $50 \mu \mathrm{M}, 25 \mathrm{~min})$ demonstrating the increase in the baseline latency of the $\mathrm{N}_{1}$ potential produced by buspirone. $B$, Group mean latency of the $\mathrm{N}_{1}$ potential in drug free solution (Pre), following buspirone application (Busp) and after wash with drug free solution $(n=4)$. Paired $t$ tests indicate that the increased $\mathrm{N}_{1}$ latency produced by buspirone is reliably different from predrug baseline $(t=3.73, d f=3$, $p<0.05)$ and from the postdrug wash $(t=5.50, d f=3, p<0.05) . C$. Plot of the change in latency of the test $N_{1}$ potential produced by prior stimulation at various interstimulus intervals. Change in latency was determined by comparing responses with prior stimulation to those without. In drug-free solution (circles), there is an initial increase in $\mathrm{N}_{1}$ latency, indicating the fibers are refractory, followed by a decrease in latency (increase in conduction velocity) that demonstrates the supernormal period. Buspirone (triangles) increases the early period of conduction slowing and reduces the magnitude of the later period of increased conduction velocity. Repeated, paired $t$ tests indicate that these changes are reliable $(p<$ 0.05 for intervals between 5 and $30 \mathrm{msec}$ ). $D$, Superimposed test $\mathrm{N}_{1}$ responses with (arrows) and without prior stimulation ( $5 \mathrm{msec}$ interstimulus interval). In drug-free solution $(D I)$ prior stimulation at this interval decreases the latency of the $\mathrm{N}_{1}$ response. After buspirone application (D2), the same interval produces an increase in $\mathrm{N}_{1}$ latency. Calibration for $A$ and $D$ is the same.

intensity required to initiate a spike. The lack of measurable change in postsynaptic input resistance or membrane potential suggests that the attenuation of synaptic activation of these neurons by buspirone involves either effects in the afferent fibers, the presynaptic terminals, or an effect on the process of synaptic transmission (either pre- or postsynaptic).

Evidence that buspirone has presynaptic action is provided by analysis of the presynaptic component of the field potential record in the stratum radiatum (the $N_{1}$ potential). Application of buspirone produces a reversible incrcasc in the latency of the $N_{1}$ potential, indicating an alteration of the excitability of the presynaptic axons. The presynaptic action of buspirone is further supported by the observation of changes in the afferent fibers which are functionally equivalent to increased refractory period.

Because the synapses in stratum radiatum are en passant, much of the axonal surface area involves presynaptic special- izations such as voltage-sensitive $\mathrm{Ca}^{2+}$ channels. Thus, it is possible that the buspirone-induced changes in the $N_{1}$ potential may indicate altered conductances specific to presynaptic terminals. However, the present data permit the exclusion of direct action on voltage-sensitive $\mathrm{Ca}^{2+}$ channels because the presynaptic effect of buspirone is apparent when these channels are blocked by low $\mathrm{Ca}^{2+} /$ high $\mathrm{Mg}^{2+}$. These data also suggest that the action of buspirone on the presynaptic axons does not involve indirect action secondary to processes related to synaptic transmission, c.g., altcration in cxtraccllular potassium (Poolos ct al., 1985).

Previous studies comparing the effects of buspirone and 5-HT on the hippocampal population spike and on pyramidal cell membrane properties have addressed the issue of buspirone's putative agonist or antagonist properties at the $5-\mathrm{HT}_{1 \mathrm{~A}}$ site. It is well established that application of 5-HT results in a rapid hyperpolarization of pyramidal cells mediated by increased po- 


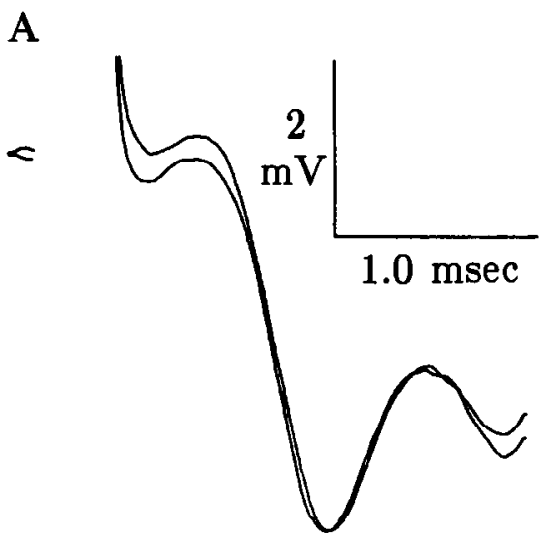

B

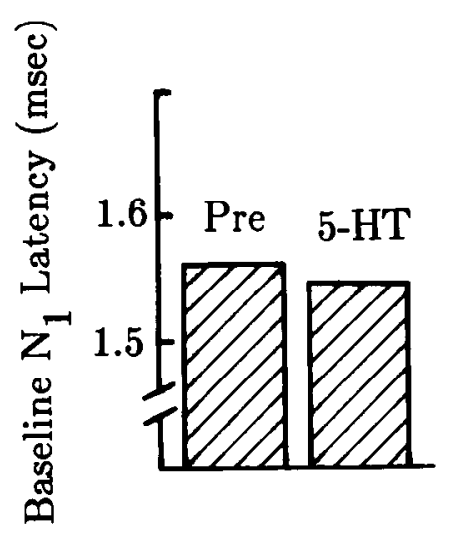

$\mathrm{C}$

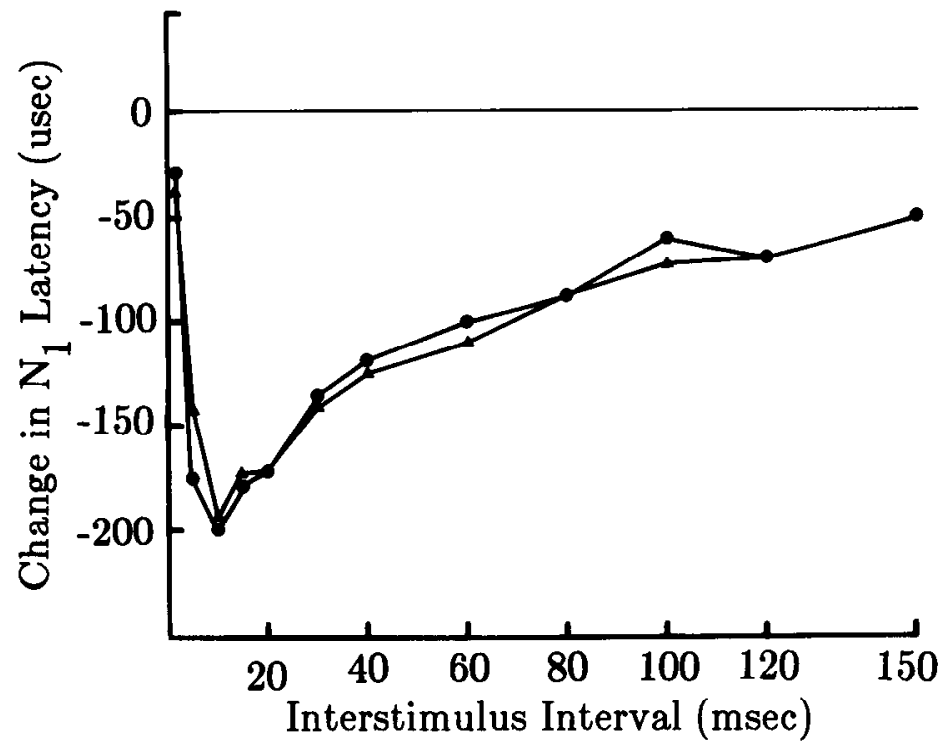

D

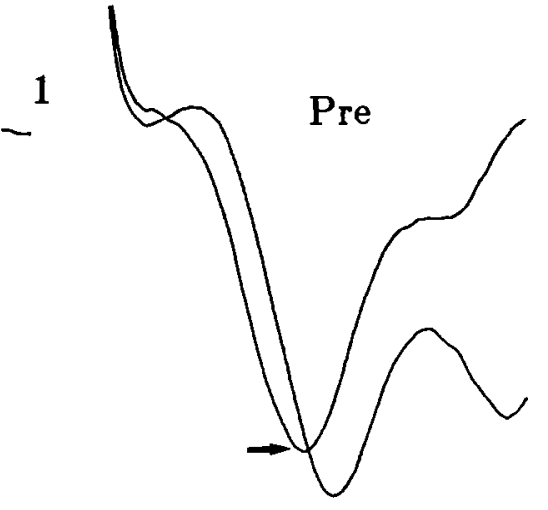

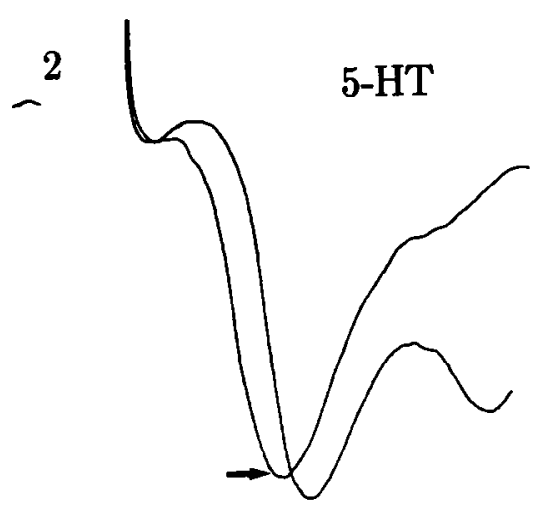

Figure 8. 5-HT application produces no measurable change in the conduction properties of the presynaptic fibers. $A$, Superimposed $N_{1}$ responses before and after (arrow) 5-HT $(100 \mu \mathrm{m}, 25 \mathrm{~min})$ demonstrating that 5-HT does not alter baseline response latency. $B$, Group mean latency of the $\mathrm{N}_{1}$ potential in drug-free solution (Pre), following 5-HT application $(5-H T)$, and after wash with drug-free solution $(n=3, d f=2, p>0.1)$. $C$, Plot of the change in latency of the test $N_{1}$ potential produced by prior stimulation at various interstimulus intervals $(n=3)$. Change in latency was determined by comparing responses with prior stimulation to those without. Responses following application of 5-HT (triangles) do not measurably differ from those in drug-free solution (circles). $D$, Superimposed test $\mathrm{N}_{1}$ responses with (arrows) and without prior stimulation (5 msec interstimulus interval). In drug-free solution $(D 1)$, and in the presence of 5-HT $(D 2)$, the decrease of the latency of the $\mathrm{N}_{1}$ response produced by prior stimulation is the same ( $p>0.1$ for all intervals). Calibration for $A$ and $D$ is the same.

tassium conductance (Segal, 1980). Buspirone decreases the amplitude of the hippocampal population spike in a dose-dependent manner (Peroutka et al., 1987; Rowan and Anwyl, 1987), suggesting a reduction in spike activity produced by excitatory input. Other studies indicate that buspirone may produce a modest hyperpolarization of pyramidal cells (Andrade and Nicoll, $1985,1987)$. On the basis of these experiments it has been proposed that buspirone may be a weak or partial agonist at the 5-HT ${ }_{1 \mathrm{~A}}$ site. Presumably, activation of this site could lead to hyperpolarization of pyramidal neurons, thereby reducing their excitability. In addition to its effects on the hippocampus, spike activity of neurons in the dorsal raphe nucleus is also decreased by buspirone (VanderMaelen and Wilderbrand, 1984; Trulson and Arasteh, 1986), and this has been presented as evidence that buspirone is an agonist at the 5- $\mathrm{HT}_{1 \mathrm{~A}}$ receptors located on raphe neurons (Dourish et al., 1986). Furthermore, neurochemical studies in rats have shown that buspirone causes a dosedependent decrease in 5-HT precursors and metabolites, evidence which was used to support an agonist effect of buspirone in rat brain (Hjorth and Carlsson, 1982; Mennini et al., 1986).
The present data suggest 2 modes of action of buspirone in the hippocampus, one involving action at 5- $\mathrm{HT}_{1 \mathrm{~A}}$ receptors and one not. Previous reports have provided evidence that the hyperpolarization produced by $5-\mathrm{HT}$ is mediated by action at $5-\mathrm{HT}_{1 \mathrm{~A}}$ receptors (Andrade and Nicoll, 1985, 1987). We found no indication that buspirone either hyperpolarizes pyramidal cells or decreases input resistance, and thus it appears buspirone is not an agonist at 5- $\mathrm{HT}_{1 \mathrm{~A}}$ sites on hippocampal pyramidal cells. However, our data suggest that buspirone attenuates the 5-HT-induced hyperpolarization of pyramidal cells which supports the notion that buspirone is an antagonist at these $5-\mathrm{HT}_{1 \mathrm{~A}}$ sites. With respect to the attenuation of synaptic activation of pyramidal cells and decrease in excitability of the afferent fibers produced by buspirone, the present data clearly indicate these effects are independent of action at 5-HT receptors. 5-HT neither shares nor antagonizes these effects of buspirone.

The present data do not exclude the possibility that the decreased synaptic activation of pyramidal cells is produced by antagonism of the postsynaptic receptors mediating the EPSP, but for several reasons this is unlikely. Application of 5-HT 


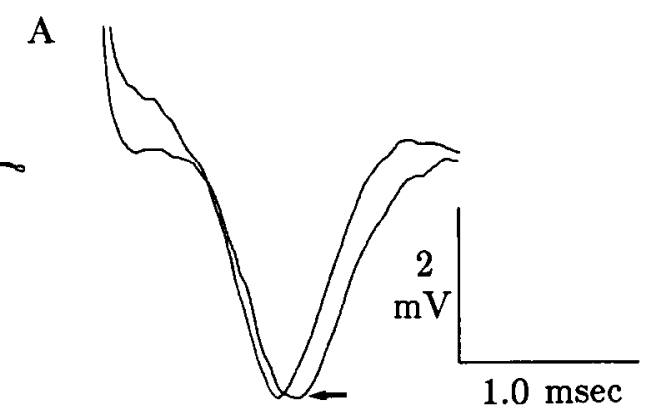

B

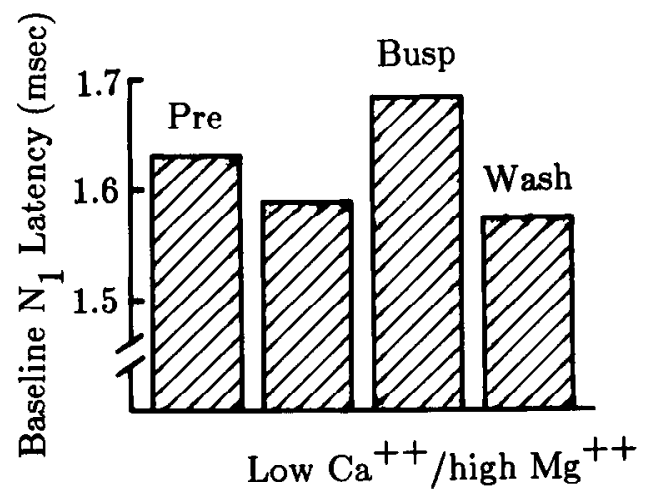

C

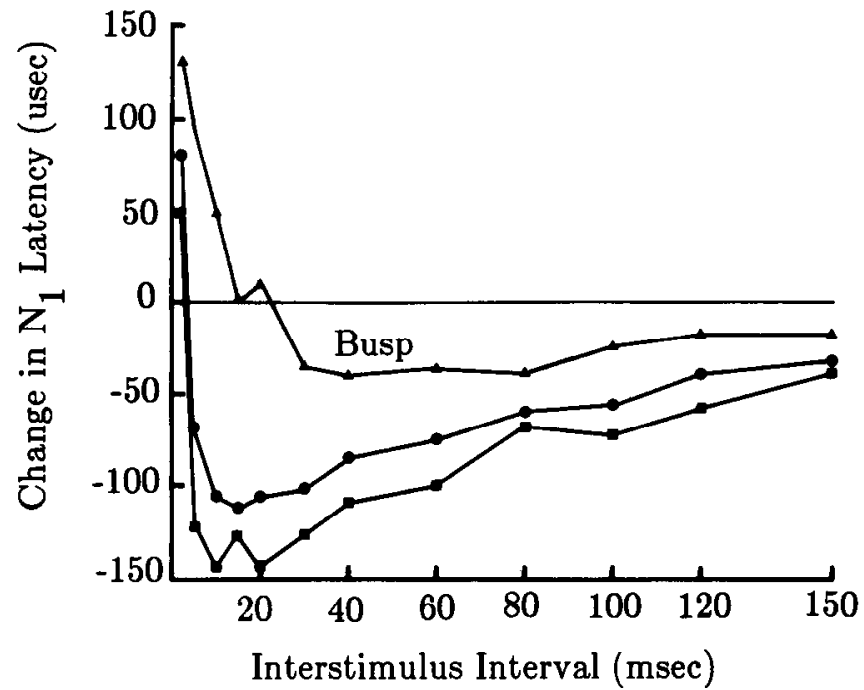

D

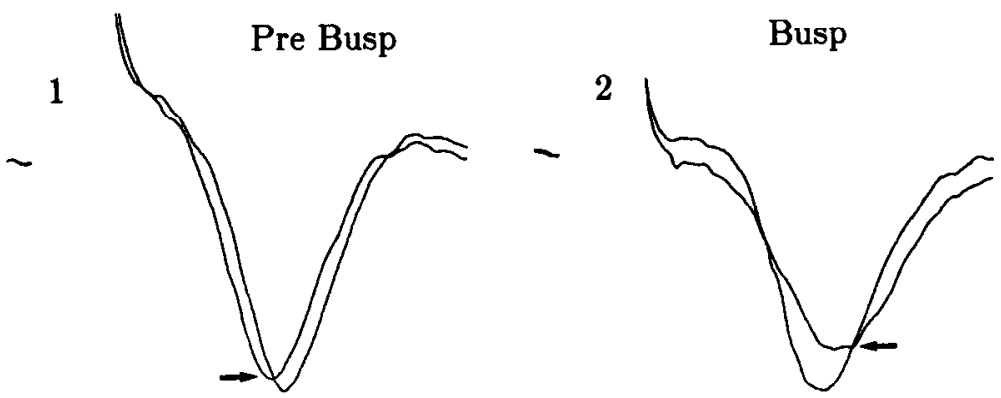

Figure 9. Effects of buspirone on the $\mathrm{N}_{1}$ potential are present when voltage-sensitive calcium currents are blocked with Kreb's solution containing

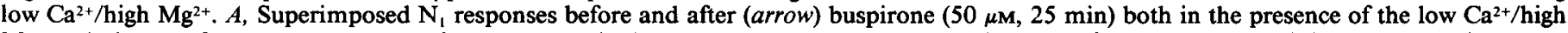
$\mathrm{Mg}^{2+}$ solution. $B$, Group mean latency of the $\mathrm{N}_{1}$ potential in normal $\mathrm{Kreb}$ s solution (Pre), in a drug-free solution containing low $\mathrm{Ca}^{2+} / \mathrm{high}^{\mathrm{Mg}}{ }^{2+}$, following buspirone application (Busp), and after wash with drug-free low $\mathrm{Ca}^{2+} / \mathrm{high}_{\mathrm{Mg}}{ }^{2+}$ solution $(n=7)$. Paired $t$ tests indicate that the following comparisons are significant $(d f=6, p<0.01)$; Pre vs low $\mathrm{Ca}^{2+} /$ high $\mathrm{Mg}^{2+}$, buspirone vs low $\mathrm{Ca}^{2+} / \mathrm{high}^{\mathrm{Mg}}{ }^{2+}$, and buspirone vs wash. $C$, Plot of the change in latency of the test $\mathrm{N}_{1}$ potential produced by prior stimulation at various interstimulus intervals. The low Ca ${ }^{2+} / \mathrm{high}^{\mathrm{Mg}} \mathrm{Mg}^{2+} \mathrm{Kreb} \mathrm{s}$ (circles; squares depict normal Kreb's) solution produces a slight attenuation of the supernormal conduction $(d f=6, p<0.05$ at $5-60$ msec intervals). Buspirone added to the low $\mathrm{Ca}^{2+} / \mathrm{high}^{\mathrm{Mg}^{2+}}$ solution (triangles) increases the early period of conduction slowing and reduces the magnitude of the later period of increased conduction velocity $(d f=6, p<0.01$ at $5-60 \mathrm{msec} ; p<0.05$ at $80-120 \mathrm{msec})$. $D$, Superimposed test $N_{\text {, responses }}$ with (arrows) and without prior stimulation ( $5 \mathrm{msec}$ interstimulus interval) in the presence of low $\mathrm{Ca}^{2+} / \mathrm{high}^{\mathrm{Mg}}{ }^{2+}$. In drug-free solution $(D I)$, prior stimulation decreases the latency of the $\mathrm{N}_{1}$ response. After buspirone application (D2), the same interval produces an increase in $\mathrm{N}_{1}$ latency. Calibration for $A$ and $D$ is the same.

hyperpolarizes pyramidal cells indicating that it is unlikely that the EPSPs elicited via afferents in the stratum radiatum are mediated by serotonergic neurotransmission. Thus, if the effects of buspirone presented here are mediated by antagonism of postsynaptic receptors, these receptors must not be serotonergic. In addition, the slow time course of buspirone's action is somewhat difficult to reconcile with such a mode of action.

The buspirone-induced decrease in conduction velocity of the presynaptic fibers could account for the attenuation of the EPSP. Conduction slowing could produce temporal dispersion in the afferent input resulting in smaller stimulation-induced EPSPs. However, it is also possible that decreased conduction velocity and increased refractory period may be secondary to changes in presynaptic fibers that directly result in decreased effectiveness in synaptic transmission.

Activation of presynaptic receptors can lead to a variety of changes that could alter synaptic transmission. For example, activation of axonal GABA receptors can lead to membrane depolarization via increased chloride conductance, alter axonal excitability, and reduce synaptic transmission (Curtis and Lodge,
1982). Indeed, the mechanism of presynaptic inhibition has been associated with the depolarizing effects of presynaptic GABA receptor activation (e.g., Levy, 1977). However, axonal excitability can be increased by such a depolarization, as evidenced by reduced threshold following presynaptic GABA receptor activation. When depolarization is pronounced, excitability can be reduced via inactivation of voltage-sensitive sodium channels. If the primary action of buspirone is via depolarization of the presynaptic fibers, one would predict a period of increased excitability of the afferent fibers when depolarization levels were low, such as that which might occur soon after buspirone application (Bhisitkul et al., 1987). It appears that buspirone does not act in this manner because a gradual and progressive reduction in excitability is observed.

Buspirone is a novel anxiolytic that lacks many of the untoward side effects of the benzodiazepines (Riblet et al., 1986). At present, the exact mechanism of action by which this unique compound derives its anti-anxiety properties is unknown. The action of the benzodiazepine anxiolytics is thought to be mediated by interaction with the benzodiazepine/GABA/chloridc 
Figure 10. Effects of buspirone on the ability of the afferent fibers in the stratum radiatum to follow high-frequency stimulation. Stimulus trains of $1 \mathrm{sec} d u-$ ration and various frequencies were delivered prior to and following buspirone application. These experiments were done in low $\mathrm{Ca}^{2+} / \mathrm{high} \mathrm{Mg}^{2+}$ to block synaptic transmission. $A$, Latency of the last response in the stimulus train is plotted as the function of the stimulation frequency $(n=4)$. The horizontal lines indicate the mean latency of the first response in each train. In low $\mathrm{Ca}^{2+} / \mathrm{high} \mathrm{Mg}^{2+}$, the fibers followed stimulation at frequencies as high as 50 $\mathrm{Hz}$ (squares). The addition of buspirone (triangles; $50 \mu \mathrm{M}, 25 \mathrm{~min}$ ) greatly reduced the frequency-following capabilities of the fibers $(d f=3, p<0.001$ for $20-50 \mathrm{~Hz}$ ). $B$ and $C$, Examples of the effects buspirone on the ability of the afferent fibers to follow $50 \mathrm{~Hz}$ stimulation. $N_{1}$ responses elicited by the first stimulus in a $1 \mathrm{sec}$ train are superimposed with responses elicited by the last stimulus (arrows). B, Control solution. $C$, Recording at 25 min after buspirone application. Calibrations for $B$ and $C$ indicate $1 \mathrm{mV}$ and $1 \mathrm{msec}$.
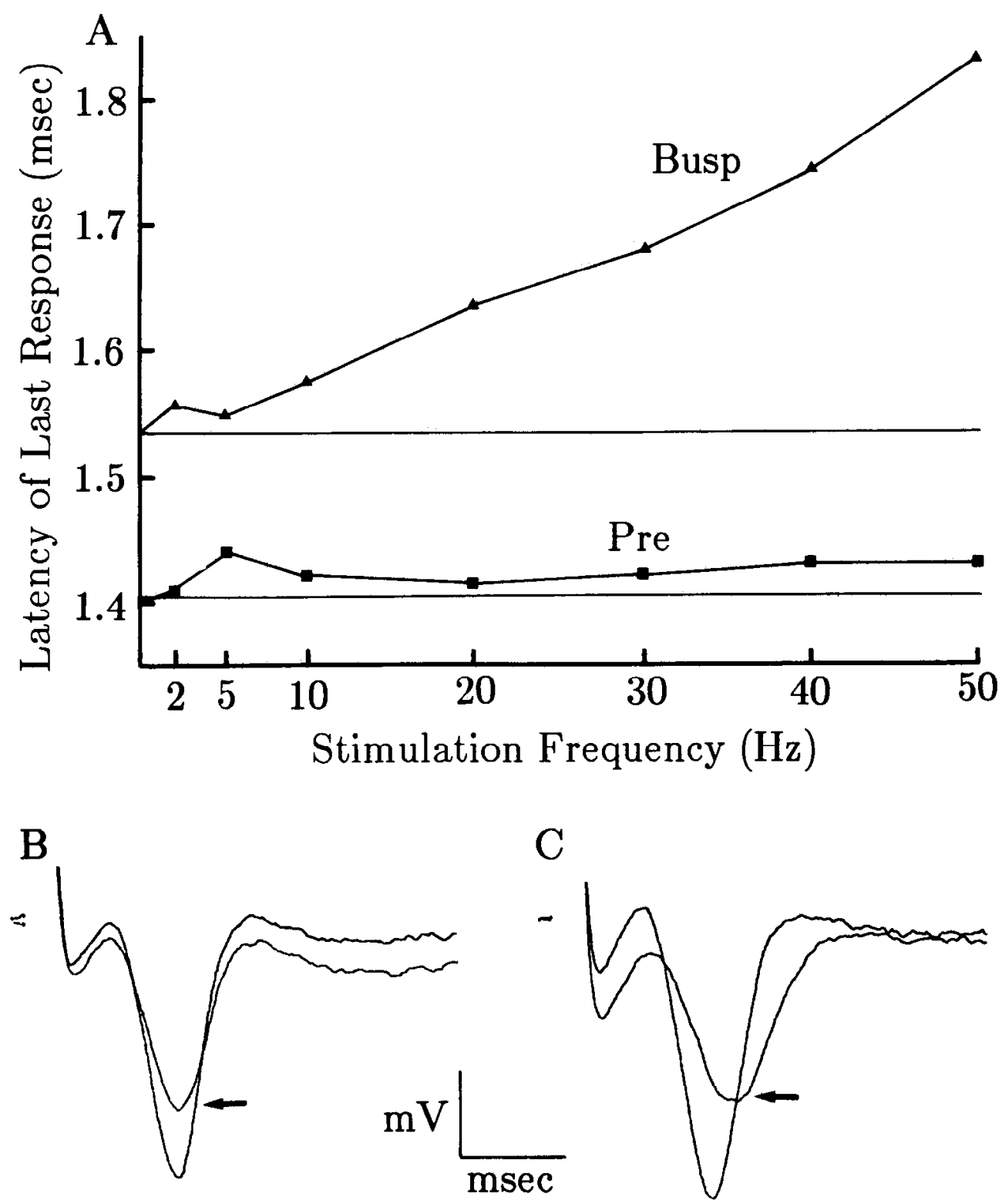

ionophore complex (e.g., Enna, 1981), yet buspirone is virtually inactive at this site (Peroutka, 1985). Thus, the anxiolytic properties of buspirone present a paradox, yet also represent a means by which the neural mechanisms of anxiety may be resolved. For example, modes of action common to substances as dissimilar as the benzodiazepines and buspirone are likely to be related to the neural mechanisms of anxiety or its reduction. The demonstration of a presynaptic action of buspirone distinct from the action of 5-HT should be of interest in these stutdies and in the evaluation of its mechanism of action.

\section{References}

Andrade, R., and R. A. Nicoll (1985) The novel anxiolytic buspirone elicits a small hyperpolarization and reduced serotonin responses at putative $5-\mathrm{HT}_{1 \mathrm{~A}}$ receptors on hippocampal CA1 cells. Soc. Neurosci. Abstr. 11: 597.

Andrade, R., and R. A. Nocoll (1987) Novel anxiolytics discriminate between postsynaptic serotonin receptors mediating different physiological responses on single neurons of rat hippocampus. Archiv. Pharmacol. 336: 5-10.

Bhisitkul, R. B., J. E. Villa, and J. D. Kocsis (1987) Axonal GABA receptors are selectively present on normal and regenerated sensory fibers in rat peripheral nerve. Exp. Brain Res. 66: 659-663.

Curtis, D. R., and D. Lodge (1982) The depolarization of feline ventral horn group Ia spinal afferent terminations of GABA. Exp. Brain Res. 46: $215-233$.

Davis, M., J. H. Kehne, and J. V. Cassella (1985) Buspirone and MJ13805 selectively attenuate fear as measured with the potentiated startle paradigm. Soc. Neurosci. Abstr. 11: 426.

Dourish, C. T., P. H. Hutson, and G. Curzon (1986) Putative anxiolytics 8-OH-DPAT, buspirone and TVX-Q7821 are agonists at $5-\mathrm{HT}_{1 \mathrm{~A}}$ autoreceptors in the raphe nuclei. Trends Pharmacol. Sci. June: $212-214$.

Enna, S. J. (1981) GABA receptor pharmacology. Biochem. Pharmacol. 30: 907-913.

Erlanger, J., and H. S. Gasser (1937) Electrical Signs of Nervous Activity, University of Pennsylvania Press, Philadelphia.

Glaser, T., and J. Taber (1983) Buspirone: Action on serotonin receptors in calf hippocampus. Eur. J. Pharmacol. 88: 137-138.

Goldberg, H. L., and R. J. Finnerty (1979) The comparative efficacy of buspirone and diazepam in the treatment of anxiety. Am. J. Psychiatry 136: 1184-1187.

Hjorth, S., and A. Carlsson (1982) Buspirone: Effects on central monaminergic transmission-possible relevance to animal experimental and clinical findings. Eur. J. Pharmacol. 83: 299-303. 
Jahnsen, H. (1980) The action of 5-hydroxytryptamine on neuronal membranes and synaptic transmission in area CAl of the hippocampus in vitro. Brain Res. 197: 83-94.

Levy, R. A. (1977) The role of GABA in primary afferent depolarization. Prog. Neurobiol. 9: 211-267.

Mennini, T., M. Gobbi, F. Ponzio, and S. Garattini (1986) Neurochemical effects of buspirone in rat hippocampus: Evidence for selective activation of 5-HT neurons. Arch. Int. Pharmacodyn. 279: 40-49.

Moskowitz, H., and A. Smiley (1982) Effects of chronically administered buspirone and diazepam on driving-related skills performance. J. Clin. Psychol. 43: 45-55.

Pazos, A., and J. M. Palacios (1985) Quantitative autoradiographic mapping of serotonin receptors in the rat brain. I. Serotonin-1 receptors. Brain Res. 346: 205-230.

Peroutka, S. J. (1985) Selective interaction of novel anxiolytics with 5-hydroxytryptamine ${ }_{1 \mathrm{~A}}$ receptors. Biol. Psychiatry 20: 971-979.

Peroutka, S. J. (1986) Pharmacological differentiation and characterization of 5- $\mathrm{HT}_{1 \mathrm{~A}}, 5-\mathrm{HT}_{1 \mathrm{~B}}$, and $5-\mathrm{HT}_{\mathrm{C}}$ binding sites in rat frontal cortex. J. Neurochem. 47: 529-539.

Peroutka, S. J., M. D. Mauk, and J. D. Kocsis (1987) Modulation of hippocampal neuronal activity by 5 -hydroxytryptamine and 5-hydroxytryptamine 1A $_{\text {A }}$ selective drugs. Neuropharmacology 26: 139146.

Poolos, N. P., D. L. Eng, M. D. Mauk, and J. D. Kocsis (1985) Postsynaptically-mediated increases in extracellular potassium modulate presynaptic excitability in hippocampus. Soc. Neurosci. Abstr. 346: 18.

Poolos, N. P., M. D. Mauk, and J. D. Kocsis (1987) Activity-evoked increases in extracellular potassium modulate presynaptic excitability in the CA1 region of the hippocampus. J. Neurophysiol. 58: 404416.

Riblet, L. A., A. S. Eison, M. D. Eison, D. P. Taylor, D. L. Temple, and C. P. VanderMaelen (1984) Neuropharmacology of buspirone. Psychopathology 17: 69-78.

Rowan, M. J., and R. Anwyl (1987) Neurophysiological effects of buspirone and isapirone in hippocampus: Comparison with 5-hydroxytryptamine. Eur. J. Pharmacol. 132: 93-96.

Schuckit, M. A. (1984) Clinical studies of buspirone. Psychopathology 17: 61-68.

Segal, M. (1980) The action of serotonin in the rat hippocampal slice preparation. J. Physiol. (Lond.) 303: 423-439.

Swadlow, H. A., J. D. Kocsis, and S. G. Waxman (1980) Modulation of impulse conduction along the axonal tree. Annu. Rev. Biophys. Bioengin. 9: 143-179.

Trulson, M. E., and K. Arasteh (1986) Buspirone decreases the activity of 5-hydroxytryptamine-containing dorsal raphe neurons in vitro. J. Pharm. Pharmacol. 38: 380-382.

VanderMaelen, C. P. (1985) Serotonin. In Neurotransmitter Actions, M. A. Rogawski and J. L. Baker, eds., pp. 201-240, Plenum, New York.

VanderMaelen, C. P., and R. C. Wilderbrand (1984) Buspirone, a nonbenzodiazepine anxiolytic drug, causes inhibition of serotonergic dorsal raphe neurons in the rat brain slice. Soc. Neurosci. Abstr. 10: 259.

VanderMaelen, C. P., D. P. Taylor, G. A. Gehlback, and M. S. Elson (1986) Non-benzodiazapine anxiolytics: Insights into possible mechanisms of action. Psychopharm. Bull. 22: 807-812. 